\title{
The genetics of systemic lupus erythematosus and implications for targeted therapy
}

\author{
Andrea L Sestak, ${ }^{1}$ Barbara G Fürnrohr, ${ }^{2}$ John B Harley, ${ }^{3,4}$ Joan T Merrill, ${ }^{5}$ \\ Bahram Namjou ${ }^{6}$
}

1Department of Pediatrics,

University of Oklahoma Health

Sciences Center, Oklahoma City,

Oklahoma, USA

${ }^{2}$ Department of Internal

Medicine 3, Institute for

Clinical Immunology, Friedrich-

Alexander-University Erlangen-

Nuremberg, Erlangen, Germany

${ }^{3}$ Cincinnati Children's Hospital

Medical Center, Cincinnati,

Ohio, USA

${ }^{4}$ US Department of Veterans

Affairs Medical Center,

Cincinnati, Ohio, USA

${ }^{5}$ Department of Clinical

Pharmacology, Oklahoma

Medical Research Foundation,

Oklahoma City, Oklahoma, USA

${ }^{6}$ Department of Arthritis and

Immunology, Oklahoma Medica

Research Foundation, Oklahoma

City, Oklahoma, USA

\section{Correspondence to}

Dr Andrea L Sestak,

Rheumatology Division

Department of Pediatrics,

University of Oklahoma Health

Sciences Center, Oklahoma City,

OK 73104, USA:

Andrea-sestak@ouhsc.edu

Accepted 15 August 2010

\section{ABSTRACT}

Observations of familial aggregation $(\lambda s=8-29)$ and a $40 \%$ identical twin concordance rate prompted recent work towards a comprehensive genetic analysis of systemic lupus erythematosus (SLE). Since 2007, the number of genetic effects known to be associated with human lupus has increased by fivefold, underscoring the complexity of inheritance that probably contributes to this disease. Approximately 35 genes associated with lupus have either been replicated in multiple samples or are near the threshold for genome-wide significance $\left(p>5 \times 10^{-8}\right)$. Some are rare variants that convincingly contribute to lupus only in specific subgroups. Strong associations have been found with a large haplotype block in the human leucocyte antigen region, with Fc $\gamma$ receptors, and with genes coding for complement components, in which a single gene deletion may cause SLE in rare familial cases and copy number variation is more common in the larger population of SLE patients. Examples of newly discovered genes include ITGAM, STAT4 and MECP2/IRAK1. Ongoing studies to build models in which combinations of associated genes might contribute to specific disease manifestations should contribute to improved understanding of disease pathology. In addition, pharmacogenomic components of ongoing clinical trials are likely to provide insights into fundamental disease pathology as well as contributing to informed patient selection for targeted treatments and biomarkers to guide dosing and gauge responsiveness. Besides these potentially valuable new insights into the pathophysiology of an enigmatic, potentially deadly, and, as yet, unsolved disease, genetic studies are likely to suggest novel molecular targets for strategic development of safer and more effective therapeutics.

Before 2007, nine established lupus susceptibility genes and genetic regions had been identified. Human leucocyte antigen (HLA) typing work in the 1970s identified genes encoded in the major histocompatibility complex region as being of potential importance in systemic lupus erythematosus (SLE), and this conclusion has been supported by the majority of the linkage and association studies conducted since (see Sestak et al ${ }^{1}$ for review). In addition to the class I, II and III HLA molecules themselves, tumour necrosis factor (TNF) $\alpha$ and complement proteins C2 and C4 lie within this highly linked region. ${ }^{2}$ Depletion of complement has long been known to be a feature of SLE, and these genes were also heavily studied before the onset of modern genetic technology. The strongest single genetic risk factor for SLE is a complete deficiency of one of the early complement components of the classic pathway such as $\mathrm{C} 1 \mathrm{q}, \mathrm{C} 2, \mathrm{C} 4 \mathrm{~A}$ and $\mathrm{C} 4 \mathrm{~B},{ }^{3-5}$ even though these deficiencies are relatively rare, only $1-2 \%$ in most cohorts. ${ }^{6} 7$ Despite this longstanding knowledge of association, however, targeted therapy has not been pursued in this area. For most patients, complement levels are low due to consumptive processes, not germline defects, and supplementing serum complement with recombinant protein would only feed the fire. ${ }^{8}$ Early linkage studies pointed to the importance of three additional genes in the aetiology of SLE; the Fc $\gamma$ receptors, which lie in a linkage region on chromosome $1 \mathrm{q} 23,{ }^{9}$ and PDCD1, which is found in the $2 \mathrm{q} 35-37$ linkage region. ${ }^{10}$ Missense mutations of FCGR2A (H131R) or FCGR3A (F176) alter their affinity to individual IgG subclasses ${ }^{11}$ and are thought to influence the processing of immune complexes and foster autoimmunity. A disease-associated non-coding single-nucleotide polymorphism (SNP) in PDCD1 alters its expression levels through disruption of DNA binding to runt-related transcription factor 1 , and this altered expression is thought to disturb the self-tolerance mechanism, leading to autoimmunity in both lupus and rheumatoid arthritis (RA). ${ }^{12} 13$

The final two genes well established before the genome-wide association scan era were discovered through candidate gene studies. Protein tyrosine phosphatase non-receptor 22 (PTPN22) contributes to risk in a number of autoimmune diseases, and in 2004 it was described in rapid succession to associate with SLE, ${ }^{14}$ RA, ${ }^{15}$ type I diabetes ${ }^{16}$ and autoimmune thyroid disease. ${ }^{17}$ Since the associated allele (R620W) leads to gain of function, ${ }^{18} 19$ there is an ongoing search for phosphatase inhibitors that may have anti-inflammatory potential through downregulating this pathway, one of which is gold. ${ }^{20} 21$ Interferon regulatory factor 5 (IRF5) became a target of interest after the discovery that SLE patients tend to upregulate interferon-induced gene transcripts. ${ }^{22} 23$ In European-derived samples three major susceptibility polymorphisms have been identified ${ }^{24}$ : rs2046400 creates a new splice site $^{25}$ rs10954213 creates a polyadenylation site, producing a shorter and more stable transcript; ${ }^{26}$ and a 30-bp insertion/deletion of exon 6 influences transcription initiation of several target genes. ${ }^{27}$ Functional work determining the relative impact of these variants remains to be pursued before IRF5 can be considered a therapeutic target.

\section{RECENT ADVANCES IN LUPUS GENETICS}

Since 2007, seven genome-wide association studies (GWAS) have been completed and published for SLE, the first five in European-derived populations and the last two in Asians. ${ }^{28-34}$ Running simultaneously with the GWAS in SLE were eight scans in 
RA, also in populations of various racial origins, revealing both unique genes and loci that appear common to these autoimmune disease.$^{35-42}$ Genome scan technology is improving in areas such as the detection of copy number variation, which is an important feature of $\mathrm{C} 4$ contribution to risk in $\mathrm{SLE}^{43}$ and may contribute to additional loci, such as the family of Fcy receptors. ${ }^{44-46}$ Although many risk haplotypes have been identified through genome-wide scans, candidate causal variants are not immediately obvious for the vast majority of them. Deep sequencing is in progress to recover rare causal variants suspected to hold some of the missing genetic causality.

Primarily through the work done in these GWAS, the number of convincingly associated genes for lupus has been raised to more than 30 (see table 1). In addition, genes that have previously or simultaneously been identified to contribute to SLE susceptibility by candidate gene or linkage approaches were corroborated by GWAS. There are a number of SLE-associated genes in the major histocompatibility complex region, and whether these associations reflect the effect of HLA-DR or make independent contributions to disease pathology remains to be determined. ${ }^{47}$ Recent attention has been focused on newly identified genes such as BANK1, IRAK1/MECP2, ITGAM, MECP2, STAT4 and TNFAIP3, and we will briefly describe these below.

\section{BANK1}

B-cell scaffold protein with ankyrin repeats (BANK1) is tyrosine phosphorylated through the B-cell receptor (BCR) upon B-cell

Table 1 Genes associated with SLE

\begin{tabular}{|c|c|c|c|}
\hline Gene & Chromosome & Published $\mathrm{p}$ value & Published OR \\
\hline BANK1 & $4 q 24$ & $3.7 \times 10^{-10}$ (EU) & 1.4 \\
\hline$B L K$ & $8 p 23.1$ & $7.0 \times 10^{-10}(\mathrm{EU})$ & 1.22 \\
\hline$C 1 q$ & $6 \mathrm{p} 21.32$ & & $\sim 5-10$ \\
\hline C2 & $6 p 21.32$ & & $\sim 5-10$ \\
\hline$C 4 A / B$ & $6 p 21.32$ & & $\sim 5-10$ \\
\hline$C R P$ & $1 q 23.2$ & $6.41 \times 10^{-7}(\mathrm{AA})$ & 0.49 \\
\hline ETS1 & $11 \mathrm{q} 24.3$ & $1.77 \times 10^{-25}(\mathrm{AS})$ & 1.37 \\
\hline FcGR2A-FcGR3A & $1 q 23.2$ & $6.78 \times 10^{-7}(\mathrm{EU})$ & 0.74 \\
\hline FcGR3B & $1 \mathrm{q} 23.2$ & $2.7 \times 10^{-8}(\mathrm{EU})$ & - \\
\hline HIC2-UBE2L3 & $22 q 11.21$ & $7.53 \times 10^{-8}(\mathrm{EU})$ & 1.22 \\
\hline$H L A-D R 2$ and $D R 3$ & $6 p 21.32$ & $1.71 \times 10^{-52}(\mathrm{EU})$ & 2.36 \\
\hline IKZF1 & $7 p 12.2$ & $2.75 \times 10^{-23}(\mathrm{AS})$ & 0.72 \\
\hline IL-10 & $1 q 32.1$ & $4.0 \times 10^{-8}(\mathrm{EU})$ & 1.19 \\
\hline IRAK1, MECP2 & Xq28 & $1.2 \times 10^{-8}(\mathrm{EU}, \mathrm{AS})$ & 1.39 \\
\hline IRF5 & $7 q 32$ & $4.4 \times 10^{-16}(\mathrm{EU})$ & 1.45 \\
\hline ITGAM-ITGAX & $16 p 11.2$ & $1.61 \times 10^{-23}$ (EU) & 1.62 \\
\hline JAZF1 & $7 p 15.2$ & $1.5 \times 10^{-9}(\mathrm{EU})$ & 1.19 \\
\hline KIAA1542/PHRF1 & $11 \mathrm{p} 15.5$ & $3.0 \times 10^{-10}(\mathrm{EU})$ & 0.78 \\
\hline LRRC18-WDFY4 & $10 q 11.22$ & $7.22 \times 10^{-12}(\mathrm{AS})$ & 1.24 \\
\hline$L Y N$ & $8 q 12.1$ & $5.4 \times 10^{-9}(\mathrm{EU})$ & 0.77 \\
\hline NMNAT2 & 1q25 & $1.08 \times 10^{-7}(\mathrm{EU})$ & 0.85 \\
\hline PRDM1, ATG5 & $6 q 21$ & $1.74 \times 10^{-8}(\mathrm{EU})$ & 1.19 \\
\hline PTPN22 & $1 \mathrm{p} 13$ & $9 \times 10^{-5}(\mathrm{EU})$ & 1.4 \\
\hline PTTG1 & $5 q 33.3$ & - & - \\
\hline PXK & $3 p 14.3$ & $7.10 \times 10^{-9}(\mathrm{EU})$ & 1.25 \\
\hline RASGRP3 & $2 \mathrm{p} 22.3$ & $1.3 \times 10^{-15}(\mathrm{AS})$ & 0.7 \\
\hline SLC15A4 & $12 q 24.32$ & $1.77 \times 10^{-11}(\mathrm{AS})$ & 1.26 \\
\hline STAT1, STAT4 & $2 q 32.3$ & $1.9 \times 10^{-9}(\mathrm{EU})$ & 1.55 \\
\hline TNFAIP3 & $6 q 23.3$ & $2.9 \times 10^{-12}(\mathrm{EU})$ & 2.3 \\
\hline TNFSF4 & 1q25.1 & $6.08 \times 10^{-7}(\mathrm{EU})$ & - \\
\hline TNIP1 & $5 q 33.1$ & $3.8 \times 10^{-13}(\mathrm{EU})$ & 1.27 \\
\hline TREX1 & $3 p 21.31$ & $4.1 \times 10^{-7}(\mathrm{EU})$ & $\sim 25$ \\
\hline UHRF1BP1 & $6 \mathrm{p} 21.31$ & $2.22 \times 10^{-8}(\mathrm{EU})$ & 1.17 \\
\hline$X K R 6$ & 8p23.1 & $2.51 \times 10^{-11}(\mathrm{EU})$ & 1.23 \\
\hline
\end{tabular}

AA, African-American; AS, Asian; EU, European; SLE, systemic lupus erythematosus. activation, which in turn associates with the tyrosine kinase Lyn and the calcium channel IP3R and results in calcium ion release from the stores of the endoplasmic reticulum. ${ }^{48}$ Polymorphisms in BANK1 may cause B-cell hyperresponsiveness. ${ }^{31}$

\section{IRAK1/MECP2}

The serine/threonine kinase IRAK1 (interleukin-1 receptor associated kinase) is part of the Toll/interleukin-1 receptor and nuclear factor kappa B signalling pathway by linking several immune receptors to the central adaptor protein TRAF6 (TNF receptor-associated factor 6 ). The identified X-chromosomal polymorphism C203S in IRAK1 is not in any known functional domain, however, and the association may actually be with its neighbour, methyl-CpG-binding protein 2 (MECP2). ${ }^{49} 50$ MECP2 encodes a protein that binds methylated DNA and is involved in the transcriptional regulation of methylation-sensitive genes. There is evidence for altered methylation in SLE, ${ }^{50}$ as well as differential expression of potentially methylated genes, ${ }^{51}$ although, as with IRAK1, a contributing causative SNP is not immediately obvious. Indeed, it is possible that both of these strong candidates contribute to the effect.

\section{Integrin $\alpha \mathbf{M}$}

Integrin $\alpha M$ (ITGAM) is a single-pass type I membrane protein predominantly expressed in monocytes and granulocytes that is involved in various adhesive interactions of monocytes, macrophages and granulocytes. Together with integrin chain $\beta 2$, ITGAM forms a functionally active heterodimer, the integrin $\alpha \mathrm{M} \beta 2$ molecule, a receptor for fibrinogen, factor $\mathrm{X}$ and intracellular cell adhesion molecule 1. ITGAM is perhaps more familiarly known as CD11b or complement receptor 3, the receptor for $\mathrm{iC} 3 \mathrm{~b}$ fragment that is produced during complement activation, and it thereby takes part in the uptake of complement-coated particles and the clearance of immune complexes. It was identified as genetic risk factor for SLE in the exploration of a strong linkage interval ${ }^{52}$ and independently confirmed in GWAS. ${ }^{30} 34$ The risk allele (rs1143679) in ITGAM encodes an amino acid shift $(\mathrm{R} 77 \mathrm{H})$, which was also correlated with renal, discoid and immunological manifestations in patients with SLE. ${ }^{53}$

\section{STAT4}

The association of a SNP (rs7574865) located in the third intron of signal transducer and activator of transcription 4 (STAT4) was found for SLE and RA in a case-control study, ${ }^{54}$ which was subsequently confirmed by GWAS in multiple populations of different ancestries. ${ }^{12} 3055$ STAT4 mediates the expression of genes involved in a variety of immunological pathways such as cellular differentiation, proliferation and apoptosis. ${ }^{56}$ Similar to IRAK, STAT4 can influence both innate and adaptive immune responses, as type I interferons, interleukin 12 (IL-12) and IL-23 are potent mediators of STAT4. ${ }^{57} 58$

\section{TNFAIP3}

Multiple polymorphisms for susceptibility to SLE and RA and other autoimmune-mediated diseases were recently found for TNF $\alpha$-induced protein 3 (TNFAIP3). ${ }^{40} 5960$ The gene product of TNFAIP3 is a zinc-finger A20 protein, with A20 being an ubiquitin-editing enzyme essential for proteasome degradation and termination of proinflammatory responses mediated by nuclear factor kappa B, thereby preventing inflammation.

There are many other genetic regions implicated in SLE through GWAS and candidate gene studies. Some of these associated SNP and haplotypes do not fall within coding regions, 
and their function may remain a mystery for some time. The potential cross-regulation by microRNA sequences and other epigenetic effects is just beginning to be explored. Models of gene-gene interaction are also likely to be important, as well as pathway analysis. The potential to discover equivalent effects caused by different genes in a model by their dysregulation of overlapping or congruent pathways holds a key for our understanding of both normal and perturbed immune functions.

\section{CONCLUSIONS REGARDING IMPORTANT GENES IN SLE}

The susceptibility genes identified thus far for SLE implicate a diverse array of pathways, including lymphocyte signalling, interferon response, clearance of complement and immune complexes, apoptosis, and DNA methylation. Although polymorphisms in ITGAM, IRF5 and PTPN22 offer mechanisms that provide plausible contributions to the pathogenesis of SLE, direct functional effects of many associated SNP and complete characterisation of risk haplotypes remain to be elucidated for most of the known genetic associations. Even as this characterisation proceeds, the knowledge derived from the genetic studies to date points to new avenues of therapy. When the mechanism of action for each risk polymorphism is better understood, new strategies for intervention will emerge. It should also be appreciated that whole genome scanning methods may fail to detect a number of potentially important genetic effects, and that some polymorphisms may have little impact alone but powerful disease consequences in combination.

\section{USING GENETIC INFORMATION IN THE TREATMENT OF SLE: IMPLICATIONS FOR CURRENT THERAPIES \\ Cyclophosphamide}

The best characterised use of pharmacogenomics in SLE has been the discovery of the impact of the cytochrome P450 system on cyclophosphamide therapy. Cyclophosphamide is a prodrug that requires activation by cytochrome P450 to 4-hydroxycyclophosphamide. There are many isoenzymes in P450 complex important for this bioactivation step, including CYP2B6, 2C9, 2C19, 3A4 and 3A5. ${ }^{61}$ Allelic variants in CYP2B6 have been reported to influence enzyme hydroxylation activity. ${ }^{62}$ At the other end of the pathway, detoxification of activated cyclophosphamide metabolites is mediated by aldehyde dehydrogenase and the glutathione S-transferase (GST) enzyme system. It has recently been reported that aldehyde dehydrogenase alleles strongly influence the level of cyclophosphamide cell toxicity and therefore the risk of haemorrhagic cystitis and liver toxicity (OR 11.95). ${ }^{63}$ In another study, the presence of at least one CYP2C19*2 allele was associated with a significantly lower risk of developing ovarian toxicity among lupus patients treated with pulsed cyclophosphamide therapy. ${ }^{64} 65$ Furthermore, it has been reported that the GSTP1 codon 105 polymorphism, but not GSTM1 or GSTT1 null mutations, significantly increased the risks of short-term cyclophosphamide side-effects such as myelotoxicity and gastrointestinal toxicity in lupus patients. ${ }^{66}$ As genetic screening becomes both more predictive and more cost effective, patients at high risk of cyclophosphamide toxicity might be considered better candidates for an alternative agent, such as mycophenolate mofetil (MMF).

\section{Mycophenolate mofetil}

$\mathrm{MMF}$ is a potent immunosuppressive agent used for the prevention of allograft rejection. Several studies have reported that MMF can be effective in the treatment of lupus nephritis and may have fewer side-effects than cyclophosphamide. ${ }^{67-69} \mathrm{MMF}$ is a reversible inhibitor of inosine monophosphate dehydrogenase (IMPDH), which is essential in the de novo pathway of purine biosynthesis. Although the purine salvage pathway is used in many cell types, activated lymphocytes are dependent on de novo purine synthesis. ${ }^{70} \mathrm{MMF}$ is rapidly hydrolysed to an active metabolite (mycophenolic acid) with more than $90 \%$ bioavailability by the oral route. Although not yet studied in lupus, polymorphisms in genes of the MMF metabolic pathway, such as IMPDH1 and IMPDH2, can affect the gastrointestinal tolerance profile and drug-associated neutropenia in heart transplant patients. ${ }^{71}$ Genetic profiling, therefore, also holds promise for predicting adverse responses in SLE.

\section{Azathioprine}

Azathioprine is also a prodrug, and it is metabolised to its active forms, 6-mercaptopurine (6MP) and 6-thionosinic acid by a series of enzymatic steps. ${ }^{72}$ Thiopurine S-methyltransferase (TPMT) deactivates 6MP, and TPMT deficiency is inherited as an autosomal recessive trait and is correlated with the risk of severe neutropenia, due to excessive accumulation of intracellular $6 \mathrm{MP} .^{72}$ Following description of the enzyme defect, the low TPMT enzyme activity was found to be predominantly due to three common variants in the TPMT gene. ${ }^{73} 74$ Inosine triphosphate pyrophosphatase (ITPA) is an enzyme that prevents accumulation of thioinosine metabolites by converting them to 6-thioinosine monophosphate, and deficiency of this enzyme has also been reported in patients with adverse reactions to thiopurine compounds. ${ }^{75-77}$ IPTA deficiency is usually due to a polymorphism of ITPA (Pro32Thr) more common in Asian populations (11-19\%), than in other ethnic groups such as Caucasians, Hispanics and Africans (1-7\%). It has been reported that Asians require lower doses of azathioprine compared with Caucasian patients to achieve the same concentration of active metabolites, possibly due to this polymorphism. ${ }^{77}$ Although it has been proposed that TPMT and/or ITPA screening be initiated to prevent toxic responses to azathioprine, this theoretical application of pharmacogenetics is not currently used in clinical practice, in which a much cheaper trial and error approach, closely following blood counts and liver enzymes at the initiation of therapy, seems just as effective.

\section{GENETIC INFORMATION FROM CLINICAL TRIALS}

In the past 20 years a number of targeted biological agents have been developed, including monoclonal antibodies, protein and cytokine inhibitors, and many signalling modulators have entered preclinical development for lupus, some advancing quite far into phase III trials. The ability to target nearly any protein or chemical and either imitate or block its function, sometimes with unexpected results, is bound to shed additional light on disease pathology. There are over a dozen agents in development targeting the 10 receptors and cytokines shown in table 2 , and there are dozens more currently in preclinical and clinical development. The recent discovery of new genes and genetic pathways contributing to SLE is likely to lead to the development of even more such targeted agents. The ongoing clinical trials incorporate genotyping of their subjects, such that there is the potential to correlate specific genetic polymorphisms with clinical manifestations, response to specific therapeutic interventions and adverse events. It will be fascinating to watch this field of study unfold over the next few years and to discover if these parameters are associated with known SLE genetic risk factors. In light of this potential and the ongoing efforts to generate pharmacogenomic data, the biological agents in SLE clinical trials are briefly reviewed here. 
Table 2 Some targeted biological treatments in development for SLE

\begin{tabular}{lllll}
\hline Medication & Target & Trial phase & Results & Reference \\
\hline Rituximab & CD20 & Phase II & Endpoints not met, under evaluation & 78 \\
Ocrelizumab & CD20 & Phase II & Early terminated trial: under evaluation & 79 \\
Epratuzumab & CD22 & Phase II & Dose-finding study & 80 \\
Belimumab & BLyS & Phase III & Two phase III trials met primary endpoint & 7081 \\
Atacicept & BLyS and APRIL & Phase II/III & Under evaluation & 82 \\
BG9588 & CD40 ligand & Phase I/II & Thrombotic complications & 8384 \\
Abatacept & CTLA4 & Phase II & Endpoints not met & 85 \\
Infliximab, etc & TNF & NA & Increased anti-dsDNA, anecdotal reports of & 85 \\
& & & efficacy in severe lupus & 8586 \\
Tocilizumab & IL-6R & Phase I & In progress & 87 \\
MEDI-545 & IFN $\alpha$ & Phase II & In progress & 88 \\
Rontalizumab & IFN $\alpha$ & Phase II & In progress & 89 \\
Eculizumab & C5 & Early reports & Some early evidence of possible use in TMHA \\
& & & syndromes (acquired TTP-like syndromes) & \\
Lupuzor & CD4 T cells relevant to & Phase II & Subgroup analysis indicated a possible efficacy & 90 \\
& anti-RNP production & & signal & \\
\hline
\end{tabular}

RNP, ribonuclear protein; SLE, systemic lupus erythematosus; TMHA, thrombotic microangiopathic haemolytic anaemia; TTP, thrombotic thrombocytopaenic purpura.

\section{BIOLOGICAL AGENTS TARGETING B CELLS}

Autoreactive B cells in SLE play a key role in disease pathogenesis, which leads to an increase in antibody-secreting plasma cells, hypergammaglobulinaemia and immune complex formation. This may be due to alterations in cytokine balance, either potentiated by or leading to IFN $\alpha$ hypersecretion in SLE. Therefore, targeting $\mathrm{B}$ cells has been considered a promising therapeutic approach for lupus.

\section{Anti-CD20 (rituximab)}

$\mathrm{CD} 20$ is a B-cell-specific antigen marker that is expressed on pre-B cells, naive and memory B cells, as well as on some B cells that enter the germinal centre, but not on mature plasma cells. Although first approved for the treatment of refractory nonHodgkin's lymphoma, ${ }^{91}$ it has since been shown to be effective for the treatment of RA. ${ }^{92}$ Two large phase III trials (Explorer and Lunar) recently failed to demonstrate the efficacy of rituximab in SLE, ${ }^{78}$ but the data suggested that this agent may have been effective in some subsets of patients. Pharmacogenomic studies could provide insights into differences between those who responded and those who did not.

\section{Anti-CD22}

CD22 is a transmembrane protein that appears on the cell surface at the pre-B-cell stage and is a critical regulator of B-cell receptor signalling. Epratuzumab is a humanised monoclonal antibody that binds to the third immunoglobulin domain of CD22 and it has encouraging initial findings in lupus, with $93 \%$ of patients in one series experiencing clinical improvement on the British Isles Lupus Assessment Group (BILAG) scale..$^{80}$

\section{BLyS monoclonal antibody}

Anti-B lymphocyte stimulator protein (BLyS) is a member of the TNF family. It has been reported that serum levels and gene expression of BLyS are increased in patients with SLE and correlate with disease activity. ${ }^{93} 94$ Belimumab (also called lymphoStat- $B$ or benlysta), is a fully human monoclonal antibody that inhibits the binding of BLyS to its three receptors, resulting in reduced BLyS-induced B-cell proliferation. This drug was promising for SLE treatment in phase III trials, ${ }^{70}$ and studies on other BLyS antagonists such as BAFFR-Ig and TACI-Ig (atacicept) are currently underway. ${ }^{82} 95$ Variations in response to these agents might someday be predicted by subtle genetic variability.

\section{BIOLOGICAL AGENTS TARGETING T CELLS}

An early target for the reduction of T-cell populations was the membrane bound form of CD40 ligand, which is overexpressed in the peripheral lymphocytes of patients with active SLE. ${ }^{96-98}$ Hu5c, IDEC-131 and BG9588 are anti-CD40L monoclonal antibodies that were promising in experimental studies but failed in clinical trials, mostly because of thrombotic complications. ${ }^{83} 99$ The thrombotic complications are thought to result from the presence of CD40L on platelets, such that anti-CD40 reagents might avoid clotting side-effects.

Another agent targeting T cells is abatacept (CTLA4Ig), which is approved for use in RA. Primary results in a murine model of lupus showed a delay in disease progression. ${ }^{100} \mathrm{~A}$ phase II trial of abatacept failed to meet its primary endpoints and the data are currently under evaluation. ${ }^{101}$ Belatacept, a second-generation CTLA4Ig, may have greater affinity to the CD80/CD86 ligands and is in clinical trials for organ transplantation. ${ }^{84}$

\section{BIOLOGICAL AGENTS TARGETING CYTOKINES AND COMPLEMENT COMPONENTS \\ Tumour necrosis factor alpha}

$\mathrm{TNF} \alpha$ is a proinflammatory cytokine that is essential for the production of many other cytokines and B and T-cell proliferation. Some reports suggest that agents that block TNF $\alpha$ (infliximab, etanercept and adalumimab) may cause disparate clinical outcomes, and the development of anti-double-stranded DNA and transient lupus-like syndrome makes use of these agents in lupus controversial. ${ }^{102}$

\section{Interleukin 6}

IL-6 is a potent proinflammatory cytokine produced by T cells and macrophages to stimulate B-cell proliferation, maturation and antibody secretion. It can also induce the proliferation of TH17 cells and therefore the production of IL-17, which was recently shown to play a key role in SLE and other autoimmune conditions. ${ }^{103}$ Tocilizumab (MRA, Actemra, RoActemra) is a humanised anti-IL-6R monoclonal antibody, which has been approved for RA. Recently, an open label phase I study of tocilizumab studied in 16 lupus patients was published, in which some clinical improvement was observed, ${ }^{86}$ and additional trials are underway.

There are numerous other monoclonal antibodies against cytokines implicated in autoimmune disease. Phase II trial are ongoing for two antagonists of IFN $\alpha$, MEDI- $545^{87}$ and 
rontalizumab. Monoclonal antibodies against other cytokines, such as IL-10 (B-N10) and IL-18 (ABT-325) are also in development for SLE. ${ }^{104} 105$ As better genetic models of disease pathology develop in SLE, new agents brought to trial and strategic combinations of these agents could perhaps be personalised to a given patient.

\section{Complement component C5}

In 2007, the US Food and Drug Administration approved eculizumab, a monoclonal antibody against complement component C5, for the treatment of paroxysmal nocturnal haemoglobinuria. This monoclonal antibody binds specifically to complement protein C5 and inhibits cleavage to C5a and C5b; therefore, this prevents the formation of terminal complement complex C5b-9 to induce haemolytic activity. This drug has been in early development for lupus. ${ }^{89}$

\section{THE FUTURE OF LUPUS GENETICS}

New technologies are providing tools to make rapid advances in the genetics of very complicated diseases. SLE is a complicated disorder, with many new genetic associations to consider in the evolving conceptual organisation of its pathogenesis. Genes that influence disease as well as those that influence therapeutic delivery are potentially of equal importance in optimal treatment selection and dosing. There is significant morbidity and mortality from current therapies, either because of immediate toxicities, risks from long-term, global immune suppression, or chronic progressive damage in patients who cannot always tolerate disease-ameliorating therapies. In this heterogenous population it is also well known that there is significant variation in individual patient responsiveness to treatments, but the science of using biomarkers to select optimal treatments and guide their dosing is in its infancy. Attempts to correlate the clinical course of disease with the genetic profile of the patient are currently underway. The next phase of genetic discovery will be to explore how the many genes that might be associated with disease risk may contribute to pathology, as well as how they work together or against each other. It could be that much of the variation in the presentation of SLE could be explained and predicted by genetic factors. The currently evolving information and technology has the potential to permit significant strides towards unravelling this complicated and previously unpredictable disease.

Competing interests JTM serves as a consultant for Genentech/Roche, UCB, Immunomedics, Human Genome Sciences/Glaxo Smith Kline, Bristol Myers Squibb, Cephalon and Medlmmune/Astra Zeneca; all other authors have no competing interests.

Provenance and peer review Not commissioned; externally peer reviewed.

\section{REFERENCES}

1. Sestak AL, Nath SK, Sawalha AH, et al. Current status of lupus genetics. Arthritis Res Ther 2007;9:210.

2. Shiina T, Hosomichi $\mathrm{K}$, Inoko $\mathrm{H}$, et al. The HLA genomic loci map: expression, interaction, diversity and disease. J Hum Genet 2009;54:15-39.

3. Agnello V. Association of systemic lupus erythematosus and SLE-like syndromes with hereditary and acquired complement deficiency states. Arthritis Rheum 1978;21(5 Suppl):S146-52.

4. Agnello V. Complement deficiency states. Medicine (Baltimore) 1978;57:1-23.

5. Stern R, Fu SM, Fotino M, et al. Hereditary C2 deficiency: association with skin lesions resembling the discoid lesion of systemic lupus erythematosus. Arthritis Rheum 1976;19:517-22.

6. Sullivan KE, Winkelstein JA, Ochs HD, et al. Genetically determined deficiencies of the complement system. In: Primary immunodeficiency diseases: a molecular and genetic approach. New York, NY: Oxford University Press 1999:397-416.

7. Sullivan KE, Wisnieski JJ, Winkelstein JA, et al. Serum complement determinations in patients with quiescent systemic lupus erythematosus. J Rheumatol 1996;23:2063-7.
8. Carneiro-Sampaio $\mathbf{M}$, Liphaus $B \mathrm{~L}$, Jesus $A A$, et al. Understanding systemic lupus erythematosus physiopathology in the light of primary immunodeficiencies. J Clin Immunol 2008;28(Suppl 1):S34-41.

9. Moser KL, Neas BR, Salmon JE, et al. Genome scan of human systemic lupus erythematosus: evidence for linkage on chromosome 1q in African-American pedigrees. Proc Natl Acad Sci U S A 1998;95:14869-74.

10. Prokunina L, Castillejo-López C, Oberg F, et al. A regulatory polymorphism in PDCD1 is associated with susceptibility to systemic lupus erythematosus in humans. Nat Genet 2002;32:666-9.

11. Li X, Ptacek TS, Brown EE, et al. Fcgamma receptors: structure, function and role as genetic risk factors in SLE. Genes Immun 2009;10:380-9.

12. Prokunina L, Gunnarsson I, Sturfelt G, et al. The systemic lupus erythematosusassociated PDCD1 polymorphism PD1.3A in lupus nephritis. Arthritis Rheum 2004;50:327-8.

13. Prokunina L, Padyukov L, Bennet A, et al. Association of the PD-1.3A allele of the PDCD1 gene in patients with rheumatoid arthritis negative for rheumatoid factor and the shared epitope. Arthritis Rheum 2004;50:1770-3.

14. Kyogoku C, Langefeld CD, Ortmann WA, et al. Genetic association of the R620W polymorphism of protein tyrosine phosphatase PTPN22 with human SLE. Am J Hum Genet 2004;75:504-7.

15. Begovich AB, Carlton VE, Honigberg LA, et al. A missense single-nucleotide polymorphism in a gene encoding a protein tyrosine phosphatase (PTPN22) is associated with rheumatoid arthritis. Am J Hum Genet 2004;75:330-7.

16. Smyth D, Cooper JD, Collins JE, et al. Replication of an association between the lymphoid tyrosine phosphatase locus (LYP/PTPN22) with type 1 diabetes, and evidence for its role as a general autoimmunity locus. Diabetes 2004;53:3020-3.

17. Criswell LA, Pfeiffer KA, Lum RF, et al. Analysis of families in the multiple autoimmune disease genetics consortium (MADGC) collection: the PTPN22 620W allele associates with multiple autoimmune phenotypes. Am J Hum Genet 2005;76:561-71.

18. Vang T, Congia M, Macis MD, et al. Autoimmune-associated lymphoid tyrosine phosphatase is a gain-of-function variant. Nat Genet 2005;37:1317-19.

19. Orrú V, Tsai SJ, Rueda B, et al.; Italian Collaborative Group. A loss-of-function variant of PTPN22 is associated with reduced risk of systemic lupus erythematosus. Hum Mol Genet 2009;18:569-79.

20. Wu S, Bottini M, Rickert RC, et al. In silico screening for PTPN22 inhibitors: active hits from an inactive phosphatase conformation. ChemMedChem 2009;4:440-4.

21. Karver MR, Krishnamurthy D, Bottini N, et al. Gold(I) phosphine mediated selective inhibition of lymphoid tyrosine phosphatase. J Inorg Biochem 2010;104:268-73.

22. Baechler EC, Batliwalla FM, Karypis G, et al. Interferon-inducible gene expression signature in peripheral blood cells of patients with severe lupus. Proc Natl Acad Sci U S A 2003;100:2610-15.

23. Bennett L, Palucka AK, Arce E, et al. Interferon and granulopoiesis signatures in systemic lupus erythematosus blood. J Exp Med 2003;197:711-23.

24. Graham RR, Kyogoku C, Sigurdsson S, et al. Three functional variants of IFN regulatory factor 5 (IRF5) define risk and protective haplotypes for human lupus. Proc Natl Acad Sci U S A 2007;104:6758-63.

25. Graham RR, Kozyrev SV, Baechler EC, et al.; Argentine and Spanish Collaborative Groups. A common haplotype of interferon regulatory factor 5 (IRF5) regulates splicing and expression and is associated with increased risk of systemic lupus erythematosus. Nat Genet 2006;38:550-5.

26. Cunninghame Graham DS, Manku H, Wagner S, et al. Association of IRF5 in UK SLE families identifies a variant involved in polyadenylation. Hum Mol Genet 2007; 16:579-91.

27. Kozyrev SV, Lewén S, Reddy PM, et al.; Argentine Collaborative Group; German Collaborative Group; Spanish Collaborative Group. Structural insertion/deletion variation in IRF5 is associated with a risk haplotype and defines the precise IRF5 isoforms expressed in systemic lupus erythematosus. Arthritis Rheum 2007:56:1234-41

28. Cervino AC, Tsinoremas NF, Hoffman RW. A genome-wide study of lupus: preliminary analysis and data release. Ann N Y Acad Sci 2007;1110:131-9.

29. Han JW, Zheng HF, Cui Y, et al. Genome-wide association study in a Chinese Han population identifies nine new susceptibility loci for systemic lupus erythematosus. Nat Genet 2009;:41:1234-7.

30. Harley JB, Alarcón-Riquelme ME, Criswell LA, et al.; International Consortium for Systemic Lupus Erythematosus Genetics (SLEGEN). Genome-wide association scan in women with systemic lupus erythematosus identifies susceptibility variants in ITGAM, PXK, KIAA1542 and other loci. Nat Genet 2008;40:204-10.

31. Kozyrev SV, Abelson AK, Wojcik J, et al. Functional variants in the B-cell gene BANK1 are associated with systemic lupus erythematosus. Nat Genet 2008;40:211-16.

32. Yang W, Shen N, Ye DQ, et al.; Asian Lupus Genetics Consortium. Genome-wide association study in Asian populations identifies variants in ETS1 and WDFY4 associated with systemic lupus erythematosus. PLoS Genet 2010;6:e1000841.

33. Cunninghame Graham DS, Graham RR, Manku H, et al. Polymorphism at the TNF superfamily gene TNFSF4 confers susceptibility to systemic lupus erythematosus. Nat Genet 2008;40:83-9.

34. Hom G, Graham RR, Modrek B, et al. Association of systemic lupus erythematosus with C8orf13-BLK and ITGAM-ITGAX. N Engl J Med 2008;358:900-9. 
35. Cui J, Taylor KE, Destefano AL, et al. Genome-wide association study of determinants of anti-cyclic citrullinated peptide antibody titer in adults with rheumatoid arthritis. Mol Med 2009:15:136-43

36. Gregersen PK, Amos Cl, Lee AT, et al. REL, encoding a member of the NF-kappaB family of transcription factors, is a newly defined risk locus for rheumatoid arthritis. Nat Genet 2009;41:820-3.

37. Julià A, Ballina J, Cañete JD, et al. Genome-wide association study of rheumatoid arthritis in the Spanish population: KLF12 as a risk locus for rheumatoid arthritis susceptibility. Arthritis Rheum 2008;58:2275-86.

38. Liu C, Batliwalla F, Li W, et al. Genome-wide association scan identifies candidate polymorphisms associated with differential response to anti-TNF treatment in rheumatoid arthritis. Mol Med 2008;14:575-81.

39. Wellcome Trust Case Control Consortium. Genome-wide association study of 14,000 cases of seven common diseases and 3,000 shared controls. Nature 2007:447:661-78.

40. Graham RR, Cotsapas C, Davies L, et al. Genetic variants near TNFAIP3 on 6q23 are associated with systemic lupus erythematosus. Nat Genet 2008;40:1059-61.

41. Plenge RM, Seielstad M, Padyukov L, et al. TRAF1-C5 as a risk locus for rheumatoid arthritis - a genomewide study. N Engl J Med 2007;357:1199-209.

42. Raychaudhuri S, Remmers EF, Lee AT, et al. Common variants at CD40 and other loci confer risk of rheumatoid arthritis. Nat Genet 2008;40:1216-23.

43. Yang Y, Chung EK, Wu YL, et al. Gene copy-number variation and associated polymorphisms of complement component $\mathrm{C} 4$ in human systemic lupus erythematosus (SLE): low copy number is a risk factor for and high copy number is a protective factor against SLE susceptibility in European Americans. Am J Hum Genet 2007; 80:1037-54.

44. Aitman TJ, Dong R, Vyse TJ, et al. Copy number polymorphism in Fcgr3 predisposes to glomerulonephritis in rats and humans. Nature 2006;439:851-5.

45. Fanciulli $\mathbf{M}$, Norsworthy PJ, Petretto E, et al. FCGR3B copy number variation is associated with susceptibility to systemic, but not organ-specific, autoimmunity. Nat Genet 2007;39:721-3

46. Willcocks LC, Lyons PA, Clatworthy MR, et al. Copy number of FCGR3B, which is associated with systemic lupus erythematosus, correlates with protein expression and immune complex uptake. J Exp Med 2008;205:1573-82.

47. Fernando MM, Stevens CR, Sabeti PC, et al. Identification of two independent risk factors for lupus within the MHC in United Kingdom families. PLoS Genet 2007;3:e192.

48. Yokoyama K, Su Ih IH, Tezuka T, et al. BANK regulates BCR-induced calcium mobilization by promoting tyrosine phosphorylation of IP(3) receptor. EMBO J 2002;21:83-92.

49. Sawalha $\mathbf{A H}$, Webb $\mathrm{R}$, Han $\mathrm{S}$, et al. Common variants within MECP2 confer risk of systemic lupus erythematosus. PLOS ONE 2008; 3:e1727.

50. Webb R, Wren JD, Jeffries M, et al. Variants within MECP2, a key transcription regulator, are associated with increased susceptibility to lupus and differential gene expression in patients with systemic lupus erythematosus. Arthritis Rheum 2009;60:1076-84.

51. Pan $\mathbf{Y}$, Sawalha AH. Epigenetic regulation and the pathogenesis of systemic lupus erythematosus. Transl Res 2009;153:4-10.

52. Nath SK, Han S, Kim-Howard X, et al. A nonsynonymous functional variant in integrin-alpha(M) (encoded by ITGAM) is associated with systemic lupus erythematosus. Nat Genet 2008;40:152-4.

53. Kim-Howard X, Maiti AK, Anaya JM, et al. ITGAM coding variant (rs1143679) influences the risk of renal disease, discoid rash and immunological manifestations in patients with systemic lupus erythematosus with European ancestry. Ann Rheum Dis 2010;69:1329-32.

54. Remmers EF, Plenge RM, Lee AT, et al. STAT4 and the risk of rheumatoid arthritis and systemic lupus erythematosus. N Engl J Med 2007;357:977-86.

55. Namjou B, Sestak AL, Armstrong DL, et al. High-density genotyping of STAT4 reveals multiple haplotypic associations with systemic lupus erythematosus in different racial groups. Arthritis Rheum 2009;60:1085-95.

56. Levy DE, Darnell JE Jr, . Stats: transcriptional control and biological impact. Nat Rev Mol Cell Biol 2002;3:651-62.

57. Darnell JE Jr, Kerr IM, Stark GR. Jak-STAT pathways and transcriptional activation in response to IFNs and other extracellular signaling proteins. Science 1994;264:1415-21.

58. Watford WT, Hissong BD, Bream JH, et al. Signaling by IL-12 and IL-23 and the immunoregulatory roles of STAT4. Immunol Rev 2004;202:139-56.

59. Bates JS, Lessard CJ, Leon JM, et al. Meta-analysis and imputation identifies a 109 $\mathrm{kb}$ risk haplotype spanning TNFAIP3 associated with lupus nephritis and hematologic manifestations. Genes Immun 2009;10:470-7.

60. Musone SL, Taylor KE, Lu TT, et al. Multiple polymorphisms in the TNFAIP3 region are independently associated with systemic lupus erythematosus. Nat Genet 2008; $40: 1062-4$

61. de Jonge ME, Huitema AD, Rodenhuis $S$, et al. Clinical pharmacokinetics of cyclophosphamide. Clin Pharmacokinet 2005;44:1135-64.

62. Xie HJ, Yasar U, Lundgren S, et al. Role of polymorphic human CYP2B6 in cyclophosphamide bioactivation. Pharmacogenomics J 2003;3:53-61.

63. Ekhart C, Rodenhuis S, Smits PH, et al. Relations between polymorphisms in drugmetabolising enzymes and toxicity of chemotherapy with cyclophosphamide, thiotepa and carboplatin. Pharmacogenet Genomics 2008;18:1009-15.
64. Singh G, Saxena N, Aggarwal A, et al. Cytochrome P450 polymorphism as a predictor of ovarian toxicity to pulse cyclophosphamide in systemic lupus erythematosus. $J$ Rheumatol 2007:34:731-3.

65. Takada K, Arefayene M, Desta Z, et al. Cytochrome P450 pharmacogenetics as a predictor of toxicity and clinical response to pulse cyclophosphamide in lupus nephritis. Arthritis Rheum 2004;50:2202-10.

66. Zhong S, Huang M, Yang X, et al. Relationship of glutathione S-transferase genotypes with side-effects of pulsed cyclophosphamide therapy in patients with systemic lupus erythematosus. Br J Clin Pharmacol 2006;62:457-72.

67. Ginzler EM, Aranow C, Merrill JT, et al. Toxicity and tolerability of mycophenolate mofetil (MMF) vs. intravenous cyclophosphamide (IVC) in a multicenter trial as induction therapy for lupus nephritis (LN). Arthritis Rheum 2003;48:1515.

68. Ginzler EM, Dooley MA, Aranow C, et al. Mycophenolate mofetil or intravenous cyclophosphamide for lupus nephritis. N Engl J Med 2005;353:2219-28.

69. Kapitsinou PP, Boletis JN, Skopouli FN, et al. Lupus nephritis: treatment with mycophenolate mofetil. Rheumatology (Oxford) 2004;43:377-80.

70. Anon. Belimumab: anti-BLyS Monoclonal Antibody; Benlysta; BmAb; LymphoStat-B. Drugs R D 2010;10:55-65.

71. Ohmann EL, Burckart GJ, Brooks MM, et al. Genetic polymorphisms influence mycophenolate mofetil-related adverse events in pediatric heart transplant patients. $J$ Heart Lung Transplant 2010;29:509-16.

72. Lennard L, Van Loon JA, Weinshilboum RM. Pharmacogenetics of acute azathioprine toxicity: relationship to thiopurine methyltransferase genetic polymorphism. Clin Pharmacol Ther 1989;46:149-54.

73. Tai HL, Krynetski EY, Yates CR, et al. Thiopurine S-methyltransferase deficiency: two nucleotide transitions define the most prevalent mutant allele associated with loss of catalytic activity in Caucasians. Am J Hum Genet 1996;58:694-702.

74. McLeod HL, Lin JS, Scott EP, et al. Thiopurine methyltransferase activity in American white subjects and black subjects. Clin Pharmacol Ther 1994;55:15-20.

75. Okada Y, Nakamura K, Hiromura K, et al. Pro32Thr polymorphism of inosine triphosphate pyrophosphatase gene predicts efficacy of low-dose azathioprine for patients with systemic lupus erythematosus. Clin Pharmacol Ther 2009;85:527-30.

76. Sumi S, Marinaki AM, Arenas M, et al. Genetic basis of inosine triphosphate pyrophosphohydrolase deficiency. Hum Genet 2002;111:360-7.

77. Yamamoto K, Okada Y, Nakamura K, et al. Inosine triphosphate pyrophosphatase 94C > A polymorphism: clinical implications for patients with systemic lupus erythematosus treated with azathioprine. Expert Opin Drug Saf 2010;9:447-57.

78. Merrill JT, Neuwelt CM, Wallace DJ, et al. Efficacy and safety of rituximab in moderately-to-severely active systemic lupus erythematosus: the randomized, double-blind, phase II/III systemic lupus erythematosus evaluation of rituximab trial. Arthritis Rheum 2010;62:222-33.

79. Hutas G. Ocrelizumab, a humanized monoclonal antibody against CD20 for inflammatory disorders and B-cell malignancies. Curr Opin Investig Drugs 2008;9:1206-15.

80. Dörner T, Kaufmann J, Wegener WA, et al. Initial clinical trial of epratuzumab (humanized anti-CD22 antibody) for immunotherapy of systemic lupus erythematosus. Arthritis Res Ther 2006;8:R74.

81. Trial watch: BLYS-targeted antibody shows promise in Phase III SLE trial. Nat Rev Drug Discov 2009; 8:688

82. ClinicalTrials.gov. Atacicept Phase II/III in Generalized Systemic Lupus Erythematosus (April SLE), 2010. http://www.clinicaltrials.gov/ct2/show/NCT00624338?term=atacic ept + AND+lupusgrank=2. (accessed 9 Aug 2010).

83. Kalunian KC, Davis JC Jr, Merrill JT, et al.; IDEC-131 Lupus Study Group. Treatment of systemic lupus erythematosus by inhibition of T cell costimulation with anti-CD154: a randomized, double-blind, placebo-controlled trial. Arthritis Rheum 2002;46:3251-8.

84. Vincenti F, Larsen C, Durrbach A, et al.; Belatacept Study Group. Costimulation blockade with belatacept in renal transplantation. N Engl J Med 2005;353:770-81.

85. Lateef A, Petri M. Biologics in the treatment of systemic lupus erythematosus. Curr Opin Rheumatol 2010;22:504-9.

86. Illei GG, Shirota Y, Yarboro CH, et al. Tocilizumab in systemic lupus erythematosus: data on safety, preliminary efficacy, and impact on circulating plasma cells from an open-label phase I dosage-escalation study. Arthritis Rheum 2010;62:542-52.

87. Yao Y, Richman L, Higgs BW, et al. Neutralization of interferon-alpha/beta-inducible genes and downstream effect in a phase I trial of an anti-interferon-alpha monoclonal antibody in systemic lupus erythematosus. Arthritis Rheum 2009;60:1785-96.

88. ClinicalTrials.gov. A Study to Evaluate the Efficacy and Safety of Rontalizumab in Patients with Moderately to Severely Active Systemic Lupus Erythematosus (ROSE), 2010. http://www.clinicaltrials.gov/ct2/show/NCT00962832?term = rontalizumabgran $k=1$. (accessed 9 Aug 2010).

89. Robak E, Robak T. Monoclonal antibodies in the treatment of systemic lupus erythematosus. Curr Drug Targets 2009;10:26-37.

90. Immupharma plc. PLC I. Positive Final Lupuzor Trial Results, 2009. http:// www.marketwire.com/press-release/Positive-Final-Lupuzor-Trial-Results-AIMIMM-1079107.htm. (accessed 9 Aug 2010).

91. Hainsworth JD, Burris HA 3rd, Morrissey LH, et al. Rituximab monoclonal antibody as initial systemic therapy for patients with low-grade non-Hodgkin lymphoma. Blood 2000;95:3052-6.

92. Cohen SB, Emery P, Greenwald MW, et al. REFLEX Trial Group. Rituximab for rheumatoid arthritis refractory to anti-tumor necrosis factor therapy: results of a 
multicenter, randomized, double-blind, placebo-controlled, phase III trial evaluating primary efficacy and safety at twenty-four weeks. Arthritis Rheum 2006;54:2793-806.

93. Stohl W, Metyas S, Tan SM, et al. B lymphocyte stimulator overexpression in patients with systemic lupus erythematosus: longitudinal observations. Arthritis Rheum 2003:48:3475-86.

94. Petri M, Stohl W, Chatham W, et al. Association of plasma B lymphocyte stimulator levels and disease activity in systemic lupus erythematosus. Arthritis Rheum 2008;58:2453-9.

95. Schneider P. The role of APRIL and BAFF in lymphocyte activation. Curr Opin Immunol 2005:17:282-9.

96. Desai-Mehta A, Lu L, Ramsey-Goldman R, et al. Hyperexpression of CD40 ligand by $B$ and $T$ cells in human lupus and its role in pathogenic autoantibody production. J Clin Invest 1996;97:2063-73.

97. Devi BS, Van Noordin S, Krausz T, et al. Peripheral blood lymphocytes in SLE hyperexpression of $\mathrm{CD} 154$ on $\mathrm{T}$ and $\mathrm{B}$ lymphocytes and increased number of double negative T cells. J Autoimmun 1998;11:471-5.

98. Vakkalanka RK, Woo C, Kirou KA, et al. Elevated levels and functional capacity of soluble CD40 ligand in systemic lupus erythematosus sera. Arthritis Rheum 1999;42:871-81.
99. Vincenti F, Kirk AD. What's next in the pipeline. Am J Transplant 2008;8:1972-81.

100. Finck BK, Linsley PS, Wofsy D. Treatment of murine lupus with CTLA4lg. Science 1994;265:1225-7.

101. Merrill JT, Burgos-Vargas R, Westhovens R, et al. The efficacy and safety of abatacept in patients with non-life-threatening manifestations of SLE: Results of A 12-month exploratory study. Arthritis Rheum 2010. Published Online First: 8 June 2010. doi: 10.1002/art.27601

102. Aringer M, Houssiau F, Gordon C, et al. Adverse events and efficacy of TNF-alpha blockade with infliximab in patients with systemic lupus erythematosus: long-term follow-up of 13 patients. Rheumatology (Oxford) 2009;48:1451-4.

103. Nalbandian A, Crispín JC, Tsokos GC. Interleukin-17 and systemic lupus erythematosus: current concepts. Clin Exp Immunol 2009;157:209-15.

104. Argiriadi MA, Xiang T, Wu C, et al. Unusual water-mediated antigenic recognition of the proinflammatory cytokine interleukin-18. J Biol Chem 2009;284:24478-89.

105. Llorente L, Richaud-Patin Y, García-Padilla C, et al. Clinical and biologic effects of anti-interleukin-10 monoclonal antibody administration in systemic lupus erythematosus. Arthritis Rheum 2000;43:1790-800. 


\section{A RD The genetics of systemic lupus} erythematosus and implications for targeted therapy

Andrea L Sestak, Barbara G Fürnrohr, John B Harley, Joan T Merrill and Bahram Namjou

Ann Rheum Dis 2011 70: i37-i43

doi: 10.1136/ard.2010.138057

Updated information and services can be found at:

http://ard.bmj.com/content/70/Suppl_1/i37

These include:

References This article cites 99 articles, 17 of which you can access for free at: http://ard.bmj.com/content/70/Suppl_1/i37\#BIBL

Email alerting service

Receive free email alerts when new articles cite this article. Sign up in the box at the top right corner of the online article.

\section{Notes}

To request permissions go to:

http://group.bmj.com/group/rights-licensing/permissions

To order reprints go to:

http://journals.bmj.com/cgi/reprintform

To subscribe to BMJ go to:

http://group.bmj.com/subscribe/ 